\title{
Cursos Pré-Vestibulares Comunitários: o caso do IFHEP e sua contribuição para o combate do racismo ${ }^{1}$
}

Jorge Augusto Correa Ribeiro²

\section{Resumo}

O presente artigo procura estabelecer como os Pré-Vestibulares Sociais (PVSs) podem contribuir para a formação política e tomada de consciência de jovens negros acerca do racismo. Para isso, procurou-se resgatar um breve histórico desses pré-vestibulares e foi utilizado o IFHEP- Instituto de Formação Humana e Educação Popular, localizado em Campo Grande, zona oeste do Rio de Janeiro, como o campo para a pesquisa, por entender esse espaço como um local privilegiado e que carrega na sua essência de criação um caráter progressista que objetiva a mudança social.

\author{
Palavras-chave \\ Cursos Pré-Vestibulares Comunitários; Antirracismo; IFHEP.
}

Community Pre-College Courses: the case of IFHEP and its contribution to the fight against racism

\begin{abstract}
The present article sought to establish how the Social Pre-Vestibular (PVSs) can contribute to the political formation and awareness of young blacks about racism. In order to do so, we sought to retrieve a brief history of these pre-university entrance exams and the IFHEP - Instituto de Formação Humana e Educação Popular, located in Campo Grande, western area of Rio de Janeiro, was used as the field for research, since it space as a privileged place and that carries in its essence of creation a progressive character that aims at social change.
\end{abstract}

Keywords

Social Pre-Vestibular; Anti-racist; IFHEP.

Artigo recebido: novembro de 2020

Artigo aprovado: dezembro de 2020 


\section{Introdução}

A denúncia das condições de vida do povo negro e da histórica opressão e desumanização vivida pelos descendentes da diáspora africana se amplificam, sobretudo, a partir de 1970 até os dias de hoje, sendo o esteio de iniciativas passadas, como a Frente Negra e o Teatro Experimental do Negro, tidos como exemplos antecessores.

A década de 1970 foi marco para a construção de pautas e de ações que passam pelos movimentos de denúncia, pelo ativismo político e por ações institucionais. Uma sinergia negra se materializou em movimentos que ganharam pujança e se desdobraram na concretude de iniciativas de movimentos sociais.

O pré-vestibular social é uma dessas iniciativas, tendo em vista o objetivo desses pré-vestibulares e o contexto histórico em que surgiram (em pleno processo de abertura política de 1985). Podemos construir uma linha que estabelece uma lógica de combate que combina a relação estabelecida pela desigualdade social posta na sociedade brasileira, em uma simbiose das pautas que se entrelaçam entre classe e raça, mas que surge no "grito" dos vários movimentos sociais, sobretudo do movimento negro.

Nesse sentido o IFHEP (Instituto de Formação Humana e Educação Popular) surge na década de 2010 como uma iniciativa advinda de militantes de movimentos sociais. O embrião dessa iniciativa vem de uma agenda construída pelo NSCG (Núcleo Socialista de Campo Grande), e sua história e sua participação como instrumento de combate ao racismo, se confundem com os múltiplos objetivos traçados pelo conjunto de militantes e educadores que construíram.

\section{Pré-vestibulares sociais, uma ferramenta de combate ao racismo}

Beatriz Nascimento, uma intelectual negra que trouxe várias contribuições para os estudos sobre a questão negra e para própria militância dos vários movimentos negros que aparecem nos anos de 1970, é firme em seus trabalhos pela defesa dos estudos sobre negritude, pelo 
ponto de vista do quilombo, local de libertação, sobretudo de vida e não de morte e aprisionamento, como muitos historiadores da época se atinham a descrever.

O sentido dado ao quilombo por ela ultrapassava o de lugar de refúgio de negros, do terror do aprisionamento e do trabalho forçado. Ela ampliava e procurava dar uma conotação de lugar de vivências, de procura de liberdades, de possibilidades criativas e de diálogo com a matriz da terra, com uma África, não conhecida, mas trazida na pele e na ancestralidade de um povo que, lenta e historicamente, teve suas raízes mortas, apagadas, ou mesmo negadas, como cultura ou como saberes.

O termo quilombo para ela significava um local de luta, de visibilidade, de procura e resgate de uma humanidade retirada por uma normatividade branca, europeia e colonizadora. Com isso, todo lugar que se colocasse em contraposição a essa lógica e buscasse a construção de uma consciência negra se colocava no campo da resistência. Sendo assim, o termo quilombo, passa a ter um sentido político, de ferramenta de combate ao racismo e de perpetuação e criação de liberdade.

O conceito de quilombo, na lógica de Beatriz Nascimento, se amplia e se transmuta, não só para um local de um passado histórico, mas de um local de resistência a toda uma construção cultural de aprisionamento e negação. Ratss (2006) coloca que a lógica do quilombo se transportou para as casas de culto afro-brasileiro, escolas de samba, favelas e para os movimentos sociais, pelos simbolismos que esses lugares carregam na luta pela sobrevivência e pela liberdade. Esses espaços são quilombos, lugares de essência de uma negritude que quer seu direito à vida.

O quilombo se transforma, então, em espaço de criação de coletividades negadas. O corpo negro, antes aprisionado e marginalizado, encontra nesses espaços um lugar de reconhecimento e alteridade, mas não uma alteridade forjada pelo branco colonizador, mas sim por uma alteridade negra, pois “o corpo negro plural constrói e qualifica outros espaços negros, de várias durações e extensões, nos quais seus integrantes se reconhecem" (RATSS, 2006, p.59). 
A reconstrução de uma coletividade que tem similitudes históricas na correlação de raça e classe, mas que tem na racialização o ponto chave da humanidade perdida. A unidade e a coletividade compartilhadas e a busca de uma plenitude, o direito a ser o que quiser ser. Ratss (2006, p.53) afırma que a contribuição dos estudos de Beatriz Nascimento para o pensamento sociológico foi o de inserir o negro no pensamento social.

Beatriz Nascimento coloca em discussão o pertencimento do negro a uma sociedade que historicamente o colocou à margem, e pontua a dificuldade de se conclamar a questão do negro somente como sendo uma questão de classe social. E aponta também que os locais de liberdade ${ }^{3}$, para se viver e as várias possibilidades de ser negro são quilombos.

As iniciativas de inserção do negro (como a do IFHEP) em uma sociedade que o negou direitos, nessa lógica construída por Beatriz Nascimento, são quilombos por excelência, um lugar de segurança e reconhecimento de alteridades negras. A representatividade compartilhada entre iguais.

A profundidade do silenciamento, do apagamento ou mesmo do genocídio do povo negro no Brasil não consegue simplesmente explicação somente pela teoria das classes sociais. Porém, a questão da classe social e de raça entraram em uma sintonia programática no final dos anos 1970 e começo dos de 1980.

A tradição dos partidos de esquerda era de hegemonizar o discurso de classes sociais tentando diluir a questão da raça simplesmente na luta de classes e essa associação teve uma relação de tensionamento, mas também, de trocas importantes e coletivas. Nilma Bentes ${ }^{4}$, uma liderança negra daquele período, descreve essa relação da seguinte forma:

Todo mundo sabe que, no começo, o movimento negro foi muito combatido pela esquerda, porque achavam que a gente ia dividir, que não era para formar nada porque, primeiro, era a questão social, de classe. E depois, quando não conseguiram acabar, eles tentaram aparelhar. Os partidos tentaram ficar dentro 
das entidades. Mas também não deu certo para eles. E a gente foi como o pessoal da Bahia no carnaval: abre o cotovelo e vai abrindo caminho (ALBERTI e PEREIRA, 2007,S/P).

A década de 1980 foi de suma importância para o avanço de uma pauta que contemplasse as reivindicações dos movimentos negros. Os movimentos de abertura política, as lutas pelas diretas e principalmente a constituição de 1988 foram o esteio de conquistas e de iniciativas que surgiram das muitas lutas travadas nos movimentos contestatórios.

Tanto o aparecimento de partidos que se colocavam no campo da esquerda, como os vários movimentos sociais e religiosos, como as pastorais ligadas às frações progressistas da igreja católica, tiveram protagonismo nas iniciativas surgidas, tanto no campo institucional, como no ativismo social. Nesse campo "a campanha da Fraternidade suscita, entre as Pastorais Juvenis, iniciativas em prol da cidadania educacional entre juventude negra" (CARVALHO, 2005, p.24).

Nesse período, os movimentos sociais de diferentes matizes, mas que de alguma forma se aproximavam, se encontraram com o movimento operário. Guimarães (2002, p.24) discorre que a criação do Partido dos Trabalhadores (PT) é um marco para a unificação de várias lutas políticas e sociais que se convergiram para dentro daquele novo partido.

Essa unidade de movimentos sociais ou populares ${ }^{5}$, em um local privilegiado para vários debates entre atores sociais, e sujeitos políticos de variados instrumentos de resistência e de questionamento, foi um campo fértil para iniciativas gestadas dentro dessa multiplicidade de ideias e subjetividades.

A apropriação política da raça, como uma questão de desigualdade e sua importância como um significante para as lutas sociais, empurrou e tensionou os vários instrumentos contestatórios para a construção de movimentos amplos. Isso se deu com os partidos de esquerda, a fim de que não fizessem associações simples entre classe e raça e entendessem a luta antirracista como, a priori, uma pauta complexa e 
entrelaçada com os questionamentos sobre os privilégios históricos da classe burguesa branca brasileira.

Assim, o campo da ideologia é um dos terrenos para a batalha antirracista, mas não o único. O racismo como ideologia e como instrumento biopolítico e necropolítico (MBEMBE, 2016) fez com que seu combate necessitasse de uma incursão e uma apropriação de vários instrumentos de ordem jurídica, pedagógica, acadêmica, institucional e outros.

Dessa forma, os pré-vestibulares sociais surgem a partir de reflexões que brotaram desse turbilhão de ideias e iniciativas, nos quais algumas dessas estavam sendo gestadas há anos e encontraram o fôlego necessário no processo de abertura política dos anos de 1980. Segundo Nascimento (1999, p. 68), a primeira iniciativa de um pré- vestibular fruto das reflexões advindas dos processos de exclusão que foram expostas as diferentes porções dos atores sociais foi na UFRJ. Segundo ele:

No Rio de Janeiro, esse processo se inicia na segunda metade da década de 1980, precisamente em 1986, com o projeto Universidade para Trabalhadores da Associação dos Trabalhadores em Educação da Universidade Federal do Rio de Janeiro - ASUFRJ (atual Sindicato dos Trabalhadores em Educação da Universidade Federal do Rio de Janeiro - SINTUFRJ). Dentro desse projeto surge o Curso Pré-Vestibular (NASCIMENTO, 1999, p.68).

Nascimento, em seu estudo, aponta que essa iniciativa do curso pré-vestibular, além de procurar dar instrumentos para que aqueles trabalhadores pudessem ter acesso ao conhecimento acadêmico e organizado das universidades, tinha também a preocupação de formar esses mesmos trabalhadores para atuação e intervenção crítica na sociedade. Para isso, ele “incorporou em seus conteúdos, estudos básicos sobre política, economia e sociedade, na perspectiva de contribuir para o melhor e mais crítico entendimento da realidade social" (NASCIMENTO, 1999, p.69). 
Isso aponta para importância dos pré-vestibulares sociais como instrumentos potentes de mudança na consciência política dos alunos, essa consciência significa uma grande possibilidade de crítica e entendimento sobre o establishment brasileiro. Desdobrando-se em iniciativas e ações coletivas, ou mesmo individuais, que visem intervir na realidade estabelecida no Brasil pela desigualdade racial e social.

Nessa lógica, também se percebe a possibilidade de construção de intelectuais que iriam agir na sociedade. No caso específico do pré- vestibular da antiga ASUFRJ, o ponto central era o conflito de classes e estabelecer uma relação contra hegemônica no agir e pensar. Em um plano mais concreto, podendo-se dizer assim, esses intelectuais seriam aqueles que formulariam e construiriam, junto com os trabaIhadores, as bases do pensamento para a revolução socialista.

Se existe, então, um pensamento hegemônico que possibilita a manutenção da ordem burguesa, podemos também destacar a existência de uma lógica que consegue manter o pensamento racista solidificado na estrutura do pensamento brasileiro. Nesse caso, um dos papeis que cumpre e cumpriram esses pré-vestibulares populares é o de combate a essas lógicas e verdades produzidas pelas hierarquias de poder. Cruz (2009) em seu diálogo com Gramsci, afırma:

A questão do conhecimento e da cultura é fundamental, na medida em que é através delas que a classe dominante consegue manter sua hegemonia, mais pelo convencimento do que pela repressão (CRUZ, 2009, p.4).

O intelectual, então, se apropria da cultura, constrói outra lógica, essa produzida e vivenciada pela classe trabalhadora, ou por negros e negras, que irão, através desses novos processos de subjetivação, se tornar agentes da luta antirracista e contra hegemônica.

Na década de 1990 começaram a surgir várias iniciativas advindas de vários movimentos espalhados pelo Brasil, que reivindicavam a questão cultural juntamente a racial, como um pressuposto principal. 
Duas dessas ideias foram o curso pré-vestibular Mangueira Vestibulares, no Rio de Janeiro, e o pré-vestibular com o nome de cooperativa Steve Biko ${ }^{6}$, na Bahia.

A Cooperativa Educacional Steve Biko surgiu por iniciativa de estudantes e professores negros, como o objetivo de fortalecer a luta contra o racismo (...). É uma proposta autônoma e independente, não tendo vínculo orgânico ou político. Os organizadores são das mais diversas origens (...), entretanto todos se identificam com o objetivo de combater o racismo e contribuir para a afirmação dos jovens negros (COOPERATIVA EDUCACIONAL STEVE BIKO, 1993 Apud, NASCIMENTO, 1999, p.70).

Essas iniciativas tinham um claro deslocamento da proposta anterior do SITUFRJ, esse tinha uma característica inteiramente classista, enquanto os outros dois ampliavam seu público-alvo; o da Mangueira trabalhava com a ideia de classe social (NASCIMENTO, 1999) e o da cooperativa Steve Biko já demostrava o recorte racial em sua proposta. Essas propostas influenciaram a criação, mais tarde, dos PVNCs (Pré-Vestibulares para Negros e Carentes).

O PVNC nasce em 1993, como uma iniciativa gerada de vários debates, na simbiose entre movimentos progressistas, operários e de movimentos sociais, como uma forte influência de setores progressistas da igreja católica.

É curioso destacar aqui que uma iniciativa como essa, que define a necessidade de inserção de uma população historicamente marginalizada e entende que o ensino universitário público e de qualidade sempre foi negado a essa população, tenha surgido no seio de movimentos dentro da Igreja Católica, uma vez que essa mesma igreja, por anos, teve papel importante nas decisões das políticas educacionais privadas no Brasil.

Mesmo contribuindo historicamente para a exclusão do negro de uma educação formal de qualidade, foi dentro da igreja católica, com a iniciativa de Frei David e da pastoral do negro, que começa 
se pensar em um pré-vestibular que incorporasse o caráter antirracista e de ativismo social.

Segundo Nascimento (1999, p. 76), a ideia de organização de um curso pré-vestibular para negros nasceu a partir das reflexões sobre a educação e o negro, realizadas entre 1989 e 1992, na Pastoral do Negro de São Paulo.

O debate interno de setores progressistas da igreja católica culminou com a concessão de 220 bolsas de estudo na PUC-SP (NASClMENTO, 1999). Depois disso, na Baixada Fluminense no Rio de Janeiro, sob a influência dessa iniciativa, acontece um debate em torno da criação de um pré-vestibular social que inserisse os estudantes negros nas universidades públicas cariocas.

Um padre, o frei David, e professores orgânicos a essa ideia buscaram então salas, voluntários e organizam toda a estrutura para acontecer o primeiro pré-vestibular social para negros com o nome de "Curso Pré-Vestibular para Negros e Carentes - PVNC".

O Pré-Vestibular para Negros e Carentes (PVNC), surgiu na Baixada Fluminense em 1993. em função do descontentamento de educadores com as dificuldades de acesso ao ensino superior, principalmente dos estudantes de grupos populares e discriminados. O PVNC também surgiu visando a articulação de setores excluídos da sociedade para unir a luta mais ampla pela democratização da educação e contra a discriminação racial (PVNCpré-vestibular para negros e carentes, 1999, p.4).

A ideia ganhou grande capilaridade, movimentos sociais e militantes se filiam à proposta, tendo então, em meados da década de 1990, um crescimento expressivo, transformando em um movimento social com enraizamento em vários territórios do Estado do Rio de Janeiro, indo da capital à Baixada Fluminense. Recorrendo novamente a Nascimento, ele afirma que:

A partir de 1994, com o sucesso e repercussão do trabalho realizado em 1993 - que obteve 34\% de aprovados para a UERJ, UFRJ, 
UFF e PUC-RJ - outros grupos (entidades populares, entidades do movimento negro, igrejas, educadores e ex-alunos) organizaram novos núcleos do Curso Pré-Vestibular para Negros e Carentes (...). No final de 1994, o PVNC contava com mais de 20 núcleos. Desde então vários núcleos foram criados. Na última reunião do Conselho Geral de 1998, em dezembro, o PVNC contabilizava 55 núcleos, organizados nos Municípios da Baixada Fluminense e no Município do Rio de Janeiro (NASCIMENTO, 1999, p.78).

Em sua carta de princípios, documento que posiciona claramente o PVNC, como um instrumento de questionamento da desigualdade social, e não só como um mero pré-vestibular; encontramos elementos que descrevem a realidade brasileira como uma construção histórica e cultural de garantia de privilégios e de assimetrias, mas que vê no aprofundamento democrático da garantia de uma educação pública, gratuita, laica e de qualidade um caminho para o combate a desigualdade social.

Dentre seus objetivos gerais, podemos destacar: "realizar um trabaIho de formação política, desenvolvendo atividades que contribuam para compreensão histórico-crítica da sociedade, das relações étnicas, das contradições e conflitos da realidade social" (PVNC- pré-vestibular para negros e carentes, 1999, p.6). Isso pontua o caráter de formador de consciência crítica e ativista do PVNC.

Sendo assim, o PVNC aparece como um movimento social potente, que cumpre um papel histórico de construir uma consciência crítica em seus alunos e na sociedade civil, hora conflitantes e hora aliadas pela perspectiva de raça e classe social, se solidificando no significante raça, como um elemento de partida para a reflexão a cerca das assimetrias sociais.

O PVNC é seguramente um instrumento político que marca sua história, associando-se como movimento social a vários outros, como os das lutas por moradia popular, a demarcação de terras ou mesmo pela reforma agrária e que se alinham à contestação das bases sociais de construção da sociedade brasileira, o próprio PVNC assim se posiciona: 
Com o ensino pré-vestibular e outras ações, o PVNC quer ser, em caráter geral um Movimento de luta contra qualquer forma de racismo e exclusão e, em caráter específico, uma frente de denúncia, questionamento e luta pela melhoria e democratização da educação, através da defesa do Ensino Público, gratuito e de qualidade em seus níveis fundamental, médio e superior, nos âmbitos Municipal, Estadual e Federal (PVNC- pré-vestibular para negros carentes, 1999, p.4).

A experiência do PVNC e sua importância histórica como ferramenta de combate ao racismo e às assimetrias construídas por múltiplos fatores que se apoiam também nas classes sociais, inspirou e inspira vários outros sujeitos sociais a criarem ferramentas de questionamento e de atuação social. O caso do IFHEP é um exemplo desses, pois é fruto das influências passadas no campo do movimento social e da educação.

Ainda sobre a experiência do PVNC, uma ruptura a partir de diferenças sobre o caráter mais geral desse pré-vestibular, forçou a criação da ONG EDUCAFRO. Frei Davi', que teve papel importante na formação do PVNC e uma liderança negra reconhecida, cria, com essa iniciativa, mais uma ferramenta de inserção do negro nas universidades.

A proposta do EDUCAFRO é de estabelecer uma rede de apoio onde o pedagógico com o pré-vestibular seria mais uma ferramenta disponibilizada para se combater às desigualdades sociais e raciais, contando com assessoria jurídica e convênios com instituições privadas.

Assim, ela se consolida como uma ferramenta de tensionamento político mais institucionalizada, diferenciando-se de outros pré-vestibulares sociais na ação concreta, tendo o campo do direito mais um instrumento para a disputa e por conquista de cidadania. Segundo o próprio EDUCAFRO, sua missão é:

(...) de promover a inclusão da população negra (em especial) e pobre (em geral), nas universidades públicas e particulares com bolsa de estudos, através do serviço de seus voluntários/as nos núcleos de pré-vestibular comunitários e setores da sua Sede 
Nacional, em forma de mutirão. No conjunto de suas atividades, a EDUCAFRO luta para que o Estado cumpra suas obrigações, através de políticas públicas e ações afırmativas na educação, voltadas para negros e pobres, promoção da diversidade étnica no mercado de trabalho, defesa dos direitos humanos, combate ao racismo e a todas as formas de discriminação ${ }^{8}$.

O EDUCAFRO acaba se diferenciando pontualmente dos PVNCs por se posicionar em relação à realidade pela perspectiva somente de inserção social e garantia de direitos; o conceito de cidadão, inserido na sociedade de classes, acaba pactuando (não por coincidência) com a proposta estabelecida pelos 13 anos de governo do $\mathrm{PT}^{9}$.

É uma lógica que se diferencia na ação proposta para esses alunos; a transformação social acaba se pautando pela reforma das instituições e pela criação de consensos para a convivência social, e não pela tomada radical do poder pelas frações da sociedade marginalizadas pela dupla opressão de raça e de classe. Segundo Teixeira (2013), a EDUCAFRO:
(...) preocupa-se em formar pessoas, não apenas no sentido de sua inserção no ensino superior, mas de possibilitar que essas pessoas façam a diferença. Muitos de nossos alunos não possuem conhecimentos políticos, sociais e filosóficos, de modo que a convivência com professores, políticos, padres, freis e juristas permite que o aluno tenha uma visão multidis- ciplinar da educação e da sociedade. O papel do aluno passa de marginalizado para protagonista de sua história: todo esse fundamento está baseado no ideário cristão franciscano, que orienta esta luta pela igualdade entre os povos em todas as esferas (TEIXEIRA, 2013, p.40).

Entender a importância dos pré-vestibulares sociais ou comunitários, como instrumentos de resistência e de construção de subjetividades, nos faz pensar no que Boaventura Souza Santos (2007, p.24) elenca como um dos objetivos da educação no século XXI, que seria o de construir "subjetividades rebeldes". 
O racismo como fundante e estruturante das relações sociais no Brasil, para ser combatido, requer um profundo entendimento de como ele age nos nossos processos de subjetivação, e também como ele se sedimenta no nosso agir e pensar. O papel que cumpre esse instrumento político, como os PVNCs e o próprio IFHEP, é de suma importância na formação de uma consciência crítica antirracista.

\section{IFHEP- Instituto de Formação Humana e Educação Popular}

A influência do PT e da Igreja católica na formação do IFHEP tem similitudes com a história da criação de outros pré-vestibulares sociais, especificamente no que diz respeito a como essas duas instituições agiram, ou melhor, contribuíram como instrumentos de ascensão de consciência política de alguns militantes. Tobias Tomines Farias, um dos fundadores do IFHEP, sobre a sua formação política afirma em entrevista ${ }^{10}$ que:

A minha formação, ela se dá a partir de uma exigência do evangelho... como que é a minha formação política? O meu cerco social ele se dá a partir de uma identificação, no final dos anos 70 , com a igreja de base, com uma igreja voltada pros problemas da América Latina, pros problemas da teologia da libertação... aquela igreja que contribuiu para que os indivíduos, que os atores e atrizes... contribuiu pra formação do PT, da CUT... eu sou fruto dessa igreja... a minha compreensão de realidade e a minha compreensão de intervenção na realidade se dá neste período... no momento em que a igreja estava voltada pra isso... eu estou falando de final dos anos 70, início dos anos 80, tinha então 16, 17, 18 anos... e que eu me abro pro mundo a partir de uma exigência do evangelho, na linha que nós acreditamos, nos obrigava a intervir nos rumos da sociedade ${ }^{11}$.

O relato de Tobias corrobora para a compreensão do significado político que cumpriu esses dois organismos, que tinham cada um à sua maneira, uma perspectiva de mudança social, para a criação de um mo- 
vimento de diálogo com a população, estabelecido pelo ato de educar, ou melhor, pela educação popular. De certa forma, essa experiência política da teologia da libertação e da criação do PT, vivida por Tobias, forjou nele a ideia de criação de um instrumento de mudança social.

A partir das reflexões de Vieira (2015) sobre o Núcleo Socialista de Campo Grande (NSCG) notamos que o núcleo tem na sua essência a história que se confunde com a do próprio IFHEP, por se constituir pelos mesmos atores políticos dele.

O pré-vestibular do IFHEP surge então da inquietação coletiva de um grupo de educadores e militantes de Campo Grande, como uma das ações advindas das reflexões surgidas nos debates que se apresentavam da agenda do NSCG. Também é importante destacar que esse Núcleo foi construído em uma conjuntura de ascensão do PT à presidência do Brasil.

Sobre a conjuntura e a própria criação do NSCG, Tobias faz um relato importante, que desnuda os caminhos e os processos vividos pela ascensão do projeto de esquerda do PT, e as tarefas que ainda se colocavam no horizonte que se descortinava na visão daqueles que construíram o próprio NSCG. Ele descreve que:

Primeiro assim... o Núcleo Socialista de Campo Grande é fruto de uma experiência anterior que é o núcleo do PT... em 2000, ou ainda, em 99, nós fundamos um núcleo do PT. Esse núcleo ele existiu organicamente ainda que estivesse no final da vida orgânica do PT de base, mas ele existiu até 2002... em 2002, no processo eleitoral, esse núcleo dizia claramente o seguinte: nós precisamos estar organizados para conduzir este governo, e nós dizíamos o seguinte...nós precisamos organizar, no Brasil inteiro, espaços de defesa do governo ou de orientação do governo... de levar o governo pro caminho certo...quando, em 2002, e depois quando em 2003, quando estava claro pra nós que o PT não era aquilo que nós sonhávamos, nós resolvemos deixar o PT... e existiu naquela época, a partir de Minas Gerais, mas aqui no Rio de Janeiro, referência era Victor Valla e Ivo Lebauspin... uma ideia 
de criar núcleos socialistas... a ideia era que criássemos núcleos socialistas por todo o Brasil, que não fossem ligados ao PT... em 2002... para que nós pudéssemos ajudar a mobilizar a população nessa perspectiva... nós rompemos com o partido e criamos o Núcleo Socialista de Campo Crande ${ }^{12}$.

Nas palavras de Tobias podemos perceber que as bases de criação do NSCC foram o afastamento com o projeto que se colocou no poder, mas não um rompimento total, ainda se tinha a verdadeira noção da importância de um governo progressista como o do PT, mas talvez os limites que o institucional estabelecia eram pequenos para as ambições dos educadores que estavam filiados, naquela ocasião, com a ideia de criação de um núcleo socialista.

Também se percebe a ideia de responsabilidade dos vários agentes sociais em dar sustentação ao governo de esquerda que chegava ao poder, e logo depois o afastamento, entendendo os possíveis limites que a proposta conciliatória daquele governo poderia ter.

Com isso, o NSCG surge de uma orientação para se criar vários instrumentos com uma perspectiva socialista, que continuassem mantendo o caráter questionador e que mantivessem um diálogo com as bases sociais, entendendo que ainda tinha como tarefa a construção de uma cultura contra hegemônica. Sendo assim, há um deslocamento da relação embrionária e orgânica na criação do NSCC, com o projeto popular criado e gestado na década de 1980 pelo PT.

Desde sua fundação, as reuniões mensais do NSCG se transformaram em agenda militante desse núcleo, tendo temas geradores que norteavam o debate. Em um primeiro momento dessas reuniões, logo no começo de sua formação, somente textos eram suficientes para fomentar o debate pretendido, depois com a complexidade e o aparecimento de novas tarefas e desafios, intelectuais, militantes de vários movimentos sociais, eram convidados para dinamizar os debates.

É importante novamente destacar, a influência que a igreja católica exerceu na formação do pensamento e na consciência política de al- 
guns sujeitos sociais, que criaram o IFHEP, os educadores Tobias Tomines Farias e Marina Ribeiro, são militantes frutos dessa relação, e os dois são citados como uns dos principais agentes de criação tanto do NSCG, quanto do IFHEP, e trazem consigo esse legado (VIEIRA, 2015, p.99).

Essa associação desenvolveu outras formas do fazer político, onde diferentes pautas foram vinculadas a ideia de exclusão social. Nesse sentido, foram agregados debates de classe, o combate ao racismo, ao machismo, as denúncias sobre as condições de vida da classe trabaIhadora, o direito à moradia, o direito à cidade, entre outras demandas. O NSCG, já não era mais só um local para o debate político e de formação, havia a urgência de dialogar também com a população da região.

Os agentes sociais que participavam dessas reuniões do NSCG queriam de alguma forma intervir na realidade, muitos deles participavam de outras experiências na região de pré-vestibulares. Já existia um entendimento entre eles sobre a intervenção na realidade a partir de um pré-vestibular, pedagogicamente, contra ideológico, ou melhor, com uma característica crítica. Segundo o próprio Tobias, o IFHEP surge de vários fatores, entre eles, da experiência de outros pré-vestibulares na região que aconteciam e das reflexões do NSCG.

Só que tinha duas outras experiências fundamente em Campo Grande, primeiro no Campo, ainda hoje existe, Centro de Apoio Popular da Zona Oeste, na Rua Camanducaia, tinha um Pré-Vestibular... que eu tinha dado aula... Que naquela ocasião era coordenado pela Marina Ribeiro, hoje no IBASE... Naquela ocasião já nós tínhamos construído um outro Pré-Vestibular na FEUC... Coordenado pela professora Celia Neves e professora Rose... Nessa ocasião eu era estudante da FEUC, fazia Ciências Sociais... Estávamos nesse pré-vestibular... então nós tínhamos o Núcleo Socialista de Campo Grande, nós tínhamos o Pré-Vestibular do Campo, o Pré-Vestibular da FEUC e tinha o Pré-Ensino Médio que, inicialmente, era do Campo, mas que o Campo não tinha mais espaço pra existir, ele foi pra FEUC... então o IFHEP é fruto de quatro experiências, que não são dis- 
tintas, porque claramente havia diálogo entre elas. Os espaços de formação do Pré-Vestibular do Campo, do IFHEP e do PEMP eram fantásticos... mas o que dava liga política era o Núcleo Socialista de Campo Crande. Surgiu o IFHEP... o IFHEP surge então, daquilo que a Marina Ribeiro, chama na melhor defınição que existe, de uma insanidade coletiva da junção insana e coletiva de dois Pré-Vestibulares, do Pré-Ensino Médio e do Núcleo Socialista de Campo...por que insanidade? Porque nós já nascemos pensando que a gente queria ser transgressor ${ }^{13}$.

Em Marina dos Santos Ribeiro, mulher negra e uma das fundadoras do IFHEP, percebemos a urgência que aparecia naquela conjuntura específica de atuação, de se construir um instrumento que dialogasse com a juventude periférica da região. Sua militância nas pastorais e sua formação política já a tinham levado à participação de outra experiência em pré-vestibular comunitário. Essa vivência foi fundamental para que a junção de reflexão e ação, advinda do NSCG desembocasse na ideia de outro pré-vestibular-vestibular. Segundo ela:

O IFHEP é resultado de muitos anos de militância, de atuação com educação e militância social na Zona Oeste, sobretudo aqui em Campo Grande... já trabalhava com Pré-Vestibular Comunitário, participava no Núcleo Socialista de Campo Grande, participava das pastorais sociais na igreja católica... nesse processo de trabalho com Pré-Vestibular Comunitário (...) um trabalho com juventude já... fazendo um debate sobre os direitos da juventude e o Núcleo Socialista também como esse braço mais político que a gente chamava, né? De formação política...14.

Toda a construção de pré-vestibulares sociais, advindos do debate iniciado na década de 1980, com a campanha da fraternidade de 1988, as iniciativas da PUC-SP, o PVNC e os vários movimentos negros, que trouxeram o racismo para o campo político da esquerda, de uma forma ou de outra, construíram a ideia do IFHEP. 
O IFHEP, portanto, também pode ser entendido como fruto do mosaico de experiências vividas por esses militantes que de uma forma ou de outra, naquele momento, estavam alimentando o desejo de mudança, nascido das reflexões que brotaram da ideia de uma educação para a mudança social ${ }^{15}$.

A manutenção do IFHEP é realizada por doações dos próprios militantes, de colaboradores e amigos. Eles procuram se manter fiéis a alguns princípios, entre eles, o de ter autonomia política de partidos e de não se transformarem em uma organização social nos modelos determinados pelas ONGs. Do ponto de vista do financiamento, isso faz com que o Instituto funcione com certa precariedade de recursos, mas também reforça o caráter de organização política da região que ele acaba tendo.

Sendo assim, era natural, em um contexto de ampliação de debates sobre opressões, onde as violências relacionadas tanto à opressão de gênero, quanto ao racismo entrassem na ordem dos debates propostos pelo IFHEP.

Sobre o combate ao racismo como um dos possíveis pressupostos para atuação política do IFHEP, Marina, que na sua condição de mulher e negra, é firme em afirmar que o tema é uma das molas geradoras das ações políticas do instituto.

Eu acho que tem um processo aí que precisa ser entendido, que é muito subjetivo... não é objetivo... porque o racismo na nossa sociedade, eu digo que ele não é simples, o pessoal diz que ele é muito sutil... não tem nada de sutil, né? Racismo na nossa sociedade não tem sutileza, pelo contrário, ele nos anula e nos agride desde a nossa existência... então, assim... como tema eu posso dizer a você que ele sempre foi um tema no Pré-Vestibular e no IFHEP... como tema... vamos discutir a questão de gênero, vamos discutir a questão de classe, as diferentes desigualdades como tema ${ }^{16}$.

Marina, com muita propriedade, consegue fazer conexões, sobre a relação que existe ou que se estabelece na formação histórica da 
sociedade brasileira entre raça, classe e gênero. Esse entrelaçamento acaba sendo necessário para dar conta dos diferentes debates para a construção de subjetividades políticas.

Marina é categórica em suas palavras em afirmar que o seu processo de tomada da consciência política e da sua condição de muIher, negra e periférica surge como algo que se constituiu em processos de subjetivação graduais. Isso se inicia a partir de uma tomada de consciência e de crítica ao debate feito por uma esquerda, mais institucionalizada, acostumada a secundarizar o debate de opressões e a priorizar as questões de classe.

A dificuldade dos organismos de esquerda em fazer essa associação de forma complexa, colabora para certo distanciamento de um discurso de classe, como algo que juntam negros e brancos trabalhadores.

Os espaços historicamente criados para serem instrumentos de contestação da ordem, como aqueles constituídos nos movimentos sociais e partidos de esquerda, são compostos por maioria branca. Talvez isso reforce a necessidade do exercício de diálogo e compreensão, do que hoje se convencionou chamar de "lugar de fala"17. Esse espaço associado ao processo subjetivo, que é agenciado por questões individuais e coletivas, que são ímpares, mas também divididos por muitos.

A coordenação do IFHEP tem, entre outras pessoas, duas mulheres negras e isso acaba sendo um diferencial. Além de Marina dos Santos Ribeiro, militante histórica do pré-vestibular, há também Rosineide Freitas, uma militante, ex-aluna do Campo, um dos pré-vestibulares que foram formadores do IFHEP, e que hoje é professora do Cap-Uerj e liderança do SINTUERJ.

A condição de mulheres e negras foi, nas palavras de Marina, a condição que fez a progressão e o alargamento das questões debatidas no IFHEP, a partir do diálogo com outros sujeitos políticos. O debate tensionado e mediado, por várias pautas que iam das questões macrossociais para as micro, e os próprios processos de mudanças pessoais que a militância proporciona. 
E aí o IFHEP como uma organização social e isso está na sociedade entra nesse caldo... e entra nesse caldo também de tomada de consciência... e eu vou dizer que é esse movimento que vai fazendo eu me tornar uma mulher negra... você não nasce, né? A Lélia Gonzales fala isso, né? Você não nasce uma mulher negra... você nasce roxinha, pretinha, moreninha... você não nasce uma mulher negra... e aí ela tá parafraseando a Simone de Beauvoir, que vai dizer que você não nasce uma mulher, você se torna uma mulher...e aí quando você tem o componente racial, você se torna uma mulher e uma mulher negra...não é qualquer mulher... então nesse processo todo o IFHEP tá nisso e as pessoas que estão no IFHEP tão nisso também ${ }^{18}$.

Rosineide Freitas também aponta que a presença de sujeitos políticos, como ela e Marina, são essenciais para que a pauta e as ações do IFHEP sejam pensadas e tensionadas e, como um espaço político que ele se constitui, na relação posta entre várias pessoas, o protagonismo de negras e negros é essencial para a formulação de um debate qualificado em que pese as opressões. Segundo ela:

É isso... porque o corte sempre foram as questões de classe... ou seja, a linha condutora são as questões de classe...são recortadas pelas diversas opressões, né? Sempre foi isso... a essência é essa..., mas aí, com o aprofundamento de cada uma de nós, porque os homens não trouxeram isso, as tensões começam a se aprofundar e aí a correlação de forças também começa a se modificar, né? É preciso ter mulher, é preciso ter uma mulher negra, é preciso ter um negro, sabe? ${ }^{19}$

O IFHEP acaba promovendo uma relação dialógica, em que seus militantes e professores atuam e se modificam, sendo todo esse processo espelho de uma práxis, que favorece profundas modificações naqueles que circulam em seu ambiente. 


\section{Considerações finais}

Esse artigo se inicia como um fragmento final de uma pesquisa que surge da curiosidade de entender como um pré-vestibular comunitário se tornou uma referência em Campo Grande, pelo seu posicionamento político e suas ações que ultrapassavam a sala de aula.

Para isso, busquei resgatar como esses espaços desses pré-vestibulares historicamente foram pensados, e identifiquei que eles são frutos dos vários movimentos contestatórios que atravessaram as décadas de 70 e 80, tendo o movimento negro, setores progressistas da igreja católica, movimentos sociais e partidos de esquerda exercendo, assim, uma forte influência na concepção do que seria sua a função social. Dentre essas funções, destaquei a inserção da população negra nas universidades, tentando contribuir, assim, para uma reparação histórica.

O IFHEP acabou sendo fruto de várias experiencias passadas de pré-vestibulares sociais e comunitários que direta ou indiretamente exerceram, sobre ele, uma forte influência. Com esses sujeitos e agentes de sua criação, que trouxeram em suas memórias atravessamentos de classe, de raça e de gênero, ele conseguiu reunir pessoas que entenderam aquele espaço para além da sala de aula, procurando estabelecer um contato transformador com seus alunos, pensando juntos nossa sociedade, com suas contradições e suas assimetrias, fazendo do ato de educar um caminho para a construção de sujeitos críticos que atuaram na busca de uma sociedade menos desigual.

\section{Referências}

ALBERTI, Verena. PEREIRA, Amilcar Araujo. Histórias do Movimento Negro no Brasil: Depoimentos ao CTDOC. Rio de Janeiro: Pallas; CPDOC-FCV, 2007. CARVALHO, José, COSTA, Renato e FILHO, Hélcio. Cursos Pré-vestibulares Comunitários - Espaços de mediações pedagógicas. Ed. PUC-RIO. Rio de Janeiro, 2005.

CRUZ, César Albenes de Mendonça. Sindicato e partido político em Gramsci. Argumentum, Vitória, v. 1, n. 1, p. 50-62, jul./dez. 2009. 
GUIMARÃES, Antônio Sergio Alfredo. Classes, Raças e democracia. São Paulo. Editora 34, 2012 (2a edição).

MBEMBE, Achille. Biopoder soberania estado de exceção política da morte. Arte \& Ensaios, Revista do PPGAV/EBA/UFRJ, n. 32. Dezembro, 2016.

NASCIMENTO, do Alexandre. Movimentos Sociais Educação e Cidadania: Um estudo sobre os pré-vestibulares populares. Dissertação (mestrado), UERJ - Universidade do Estado do Rio de Janeiro,1999.

RATSS, Alex. Eu sou atlântica sobre a trajetória de vida de Beatriz Nascimento. Imprensa Oficial, São Paulo, 2006.

SANTOS, Boaventura de Souza. Renovar a Teoria Crítica e Reinventar a Emancipação Social. São Paulo: Boitempo, 2007.

TEIXEIRA, Alves Willian. A trajetória da Educafro no acesso ao ensino superior e sua luta pela igualdade racial através de curso pré-vestibular popular. Cadernos cimeac - v. 3, n. 1, 2013. ISSN 2178-9770 Ribeirão Preto - SP, Brasil.

VIEIRA, Willian de Souza. Núcleo Socialista de Campo Grande: interações entre memórias e história em contexto local. Rio de Janeiro, 2015.

\section{Notas}

1 Este artigo é um fruto da dissertação de mestrado em Relações Étnico-raciais do PPRER- CEFET/RJ. RIBEIRO, Jorge Augusto Correa. Cursos pré-vestibulares comunitários e jovens da zona oeste: O Caso do IFHEP e sua contribuição ao combate ao racismo. Dissertação (mestrado). Centro de Educação Tecnológica Celso Suckow da Fonseca, 2018.

2 Mestre em relações Étnico-raciais. Professor da rede Municipal do Rio de Janeiro, Brasil. https://orcid.org/0000-0001-7030-3611. E-mail: c.ribeiro.jorge@gmail.com

3 Como afirma Alex Ratss sobre o pensamento de Beatriz Nascimento: "locus da resistência negra que se transpunha no século XX para as favelas, as escolas de samba, as casas de culto afro-brasileiro e as próprias organizações dos movimentos negros." (RATSS, 2006, p.53). Esses lugares seriam os novos quilombos.

4 Nilma Bentes foi fundadora do Centro de Estudos e Defesa do Negro do Pará (Cedenpa) e, desde então, tornou-se uma referência do movimento negro na região Norte do Brasil (ALBERTI e PEREIRA, 2007, S/P).

5 Segundo Guimarães (2002), alguns estudiosos da época, na tentativa de cunhar um termo que desse conta de juntar as classes produtivas quanto os atores sociais que estavam fora da cadeia produtiva, usavam o termo classes populares. 
6 Esse nome foi em homenagem ao líder Sul Africano, morto pelo apartheid (NASCIMENTO, 1999, p.70).

7 Desde meados da década de 1980, vem atuando em paroquias da Baixada Fluminense, no Rio de Janeiro. Participou da criação do PVNC e do EDUCAFRO. ALBERTI e PEREIRA (2007).

7 Disponivel em: https://www.educafro.org.br/site/conheca-educafro/. Acesso em 20 de julho de 2018.

8 Frei David sempre teve uma relação orgânica com o Partido dos Trabalhadores, e foi até mesmo acusado de que iria cortar bolsas de estudo para os estudantes que não fizessem campanha para o partido. Disponível em: https://odia.ig.com. br/_conteudo/noticia/opiniao/2014-10-28/frei-david-santos-por-que-o-projeto-dilma-venceu.html. Acesso em 20 de julho de 2018.

9 As entrevistas citadas nesse artigo foram gravadas em áudio, mas somente o pesquisador e o orientador tiveram acesso a elas para assegurar a confidencialidade das informações dos entrevistados, comprometendo-se assim também com o sigilo e não fazer uso destas informações para outras finalidades.

10 Entrevista concedida por Tobias Tomines Farias, em 12 de maio de 2018.

11 Entrevista concedida por Tobias Tomines Farias, em 12 de maio de 2018.

12 Entrevista concedida por Tobias Tomines Farias, em 12 de maio de 2018.

13 Apesar de não citar Paulo Freire em nenhum momento na entrevista, suas ideias de uma pedagogia que se aproximem do oprimido estavam em vários momentos na fala dos entrevistados.

14 Entrevista concedida por Marina dos Santos Ribeiro em 15 de maio de 2018

15 RIBEIRO, Djamila. O que é lugar de fala? Belo Horizonte: Letramento, Justificando, 2017.

16 Entrevista concedida por Marina dos Santos Ribeiro, em 15 de maio de 2018.

17 Entrevista concedida por Rosineide Freitas, em 4 de junho 2018. 


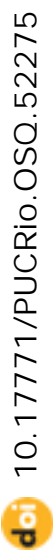

